\title{
Compensatory Effects of Boat Wake and Dredge Spoil Disposal on Assemblages of Macroinvertebrates
}

\author{
Melanie J. Bishop* \\ Centre for Research on Ecological Impacts of Coastal Cities, Marine Ecology Laboratories, A11, University \\ of Sydney, New South Wales 2006, Australia
}

\begin{abstract}
Estuarine assemblages are exposed to multiple disturbances that overlap in time and space. Along the Atlantic Intracoastal Waterway (east coast, United States), two disturbances that frequently co-occur are the production of wake by boats and the disposal of sediment dredged from boat channels. Boat wake generally coarsens sediments by eroding finer particles while deposition of dredge spoil decreases mean grain size. If previously demonstrated effects of boat wake on infauna are due to coarsening of grain size, deposition of dredge spoil on wake affected sites may, through compensatory effects, prevent an effect of wake from being detected. Epifaunal assemblages associated with seagrass blades that are more likely to be structured by hydrodynamic forces than granulometry may instead be affected by boat wake irrespective of the previous deposition of fine materials. To test these hypotheses, infauna and epifauna were sampled in patchy seagrass habitat at sites with and without boat wake that were affected by historic deposition of dredge spoil and at sites without wake that had not received dredge spoil. Sediment granulometry and infaunal assemblages differed between sites with and without dredge spoil but not between spoil affected sites differing in exposure to wake. Epifaunal assemblages differed between sites with and without wake irrespective of sediment granulometry. The effect of wake on epifauna was primarily due to lesser abundances of the gastropod Bittiolum varium and the slipper limpet, Crepidula fornicata, at wake exposed sites. These results suggest that because of their opposing effects on sediment granulometry, boat-wake and sediment disposal may have compensatory effects on infaunal assemblages. The detection of an effect of wake on epifauna despite the absence of a sedimentological effect of the disturbance shows that ecological impacts do not necessarily mirror physical effects and should be considered separately when adopting strategies of management.
\end{abstract}

\section{Introduction}

Estuaries are areas of great human activity. They support commercial and recreational fisheries, provide natural harbors and routes for transportation, and represent a valuable resource for commerce, tourism, and recreation. As coastal development continues, anthropogenic activities place increasing pressures on estuarine plants and animals. Research into the way in which these disturbances affect estuarine assemblages of plants and animals is needed so that the disturbances may be managed to minimize their ecological effect.

Most ecological impact assessments in estuaries focus on the effect of a single anthropogenic disturbance on the organism(s) of interest (Vouk et al. 1987). Almost all estuarine assemblages are exposed to multiple disturbances that overlap in time or space. Where multiple disturbances cooccur, their effects can be additive (their collective effects are equal to their sum), compensatory (one effect subtracts from another), or synergistic (their collective effect is greater than the sum of the individual effects; see Gosselink et al. 1990; Spaling

\footnotetext{
* Current address: Department of Environmental Sciences, University of Technology Sydney, Gore Hill, New South Wales 2065, Australia; tele: 6129514 4159; fax: 6129514 4079; e-mail: Melanie.Bishop-1@uts.edu. au
}

and Smit 1993). The cumulative effect of multiple disturbances cannot necessarily be predicted by adding independent effects.

Boating, like many human activities, can disturb the natural environment in a number of ways. Boats produce wake, can introduce heavy metals (associated with antifouling paints and sacrificial anodes) and polyaromatic hydrocarbons (associated with fuels) to waterways, discharge sewage, and scar beds of submerged aquatic vegetation. Marinas, which support boating, introduce structure where it would otherwise be absent, pontoons and pilings shade sediments, boat ramps and car parks increase the area of impervious surface, and the dredging of boat channels drastically alters the benthos. These disturbances associated with boating can affect the distribution and abundance of plants and animals in natural and man-made waterways (e.g., Davis 1977; Bryan et al. 1986; Walker et al. 1989; Glasby and Connell 2001; Bell et al. 2002).

Recent studies indicate that boat-generated waves can drastically alter the structure of infaunal assemblages of macroinvertebrates in estuaries (Bishop 2004; Bishop and Chapman 2004). Although the mechanism by which boat wake affects infauna was not determined, infauna may be eroded with sediments and their permanent tubes and burrows may be disrupted by sediment destabiliza- 
tion (Dobbs and Vozarik 1983). Suspension feeders may be favored by increases in suspended organic matter in wave exposed places (Bock and Miller 1994), although the resuspension of large particles can inhibit feeding (Bricelj et al. 1984; Grant and Thorpe 1991), and increases in turbidity might decrease standing stocks of microflora available to deposit feeders (MacIntyre and Cullen 1996). Effects to infauna may be a result of boat wake increasing the mean grain size of sediments in shallow waters (Garrad and Hey 1987; Nanson et al. 1994; Osborne and Boak 1999; Bauer et al. 2002). Deposit feeders are generally more abundant in muddy sediments, and sandy sediments often favor suspension-feeders (Rhoads 1974; Snelgrove and Butman 1994).

Organisms that live above the sediment are presumably less affected by changes to granulometry of the sediment. Although they may be influenced by the resuspension of organic material (Bayne et al. 1989), epifaunal organisms are most influenced by hydrodynamic forces of waves (i.e., lift and drag) that can challenge their attachment to the substrate and wash them away (e.g., Denny et al. 1985; Denny 1987, 1995). Lift and drag forces generated by boat wake may be magnified in seagrass beds where oscillating flows generated by waves can cause blades to flap back and forth at the frequency of the waves (Grizzle et al. 1996; Koch and Gust 1999).

Along the Atlantic Intracoastal Waterway (AIW), a federally maintained navigation channel that extends along the southeastern coast of the United States from Norfolk, Virginia, to Miami, Florida, boating channels are periodically dredged to allow passage of deep-draught vessels. Fine sediments dredged from the bottom of the channel are deposited on dredge spoil islands, adjacent to the navigation channel or at other land-based fill sites. Although deposition of sediments on dredge spoil islands is supratidal, slumping can spread fine sediments on to adjacent intertidal and shallow subtidal waters. Dumping of fine sediments on these islands may counteract the anticipated effect of boat wake in coarsening sediments in shallow subtidal and intertidal habitats on the islands' exposed side.

Along much of the AIW, waves generated by boats are of larger amplitude than wind-driven waves, which have been demonstrated to have a sizeable effect on macroinvertebrate assemblages (e.g., Tamaki 1987; Emerson and Grant 1991; Turner et al. 1999). In the absence of compensatory effects of co-occurring disturbances, an effect of boat wake on infaunal and epifaunal assemblages may be expected. If the main mechanism by which boat wake influences infaunal assemblages is via changes in the granulometry of the sediment, deposition of spoil may counteract effects of coarsening of sediment by boat wake on infaunal assemblages. In this case an effect of wake on epifauna associated with seagrass but not on infauna may be detected.

I investigated the role of boat wake in structuring epifaunal and infaunal assemblages of macroinvertebrates in a patchy seagrass habitat where dredged materials on spoil islands might counteract coarsening of sediments by wake. I hypothesized that assemblages of infaunal macroinvertebrates would differ between sites with and without dredge spoil, irrespective of the exposure of sites to boat wake; and assemblages of epifaunal organisms would differ between sites with and without boat wake irrespective of whether the sites are also affected by dredge spoil.

\section{Materials and Methods}

\section{STUdy SiTES}

In North Carolina, one of the natural waterways through which the AIW passes is Bogue Sound (Fig. 1). At the western end of the sound (34u409N, 77 29W), sediment has been dredged from the AIW and deposited in the middle of the Sound, forming spoil islands that have been colonized by marsh plants. These islands, which no longer receive materials dredged from the AIW, divide this part of the Sound into two 1-km wide sections: one that is exposed to the wake of vessels traveling along the AIW and one that is sheltered from boat wake.

Sampling was done at sites $25 \mathrm{~m}$ long (in the direction parallel to the shore) and $5 \mathrm{~m}$ wide, situated in shallow subtidal areas adjacent to: the northern, wake exposed side of the dredge spoil islands (+wake [W]+spoil [S]), the southern side of the dredge spoil islands, sheltered from wake $(2 \mathrm{~W}+\mathrm{S})$, and the southern bank of the sound (2W2S; Fig. 1). Although the northern bank of the sound was also sampled, it is not considered here because sand bars between the AIW and the shore complicated effects of wake. The sites had a water depth of approximately $30 \mathrm{~cm}$ at low tide, a mean tidal range of $0.89 \mathrm{~m}$, and contained fragmented beds of the eelgrass Zostera marina (L.) and the shoal grass Halodule wrightii (Ascherson). Sightings through a range finder (n 5 16) indicated that vessels traveling along the AIW were an average distance of $91610 \mathrm{~m}$ (1 SE) away from sites on the exposed side of the spoil islands. Wake produced an average maximal current speed (in a direction perpendicular to shore) of $95611 \mathrm{~cm} \mathrm{~s}^{21}$ at these sites. During sampling, I did not observe any boat traffic south of the dredge spoil islands. I assumed that generation of wind-driven waves was similar on 


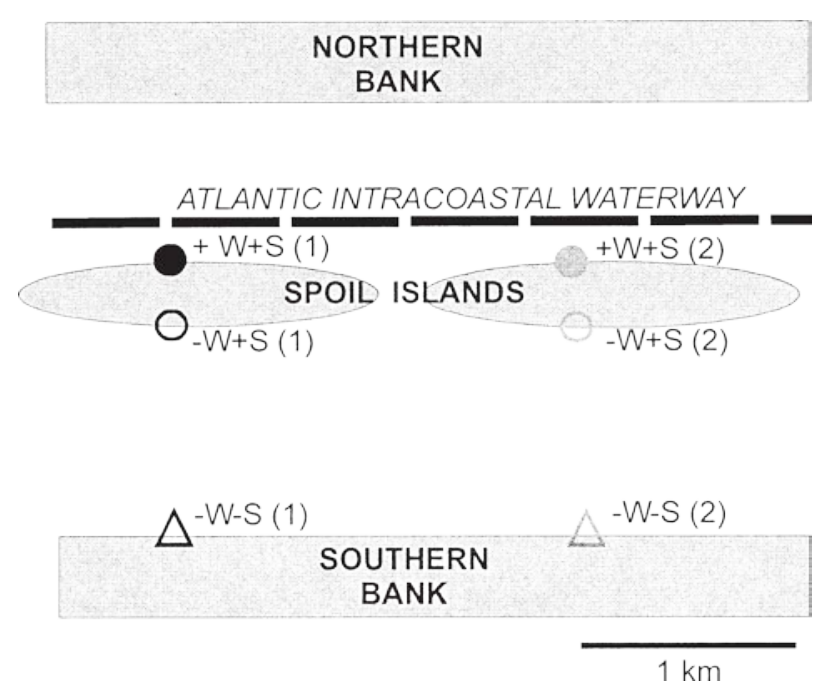

Fig. 1. Sites at Bogue Sound that were sampled in fall 2001. +W 5 with wake, 2W 5 without wake, +S 5 with spoil, and 2S 5 without spoil.

the two sides of the sound due to their similar fetches.

\section{SAMPLING METHODS}

Sediments and macroinvertebrates were sampled in fall 2001. To determine whether sediments differed between dredge spoil islands and the natural banks of the sound, irrespective of exposure to wake, three cores of sediment, $10 \mathrm{~cm}$ in depth and $2 \mathrm{~cm}$ in diameter, from each of the 6 sites were collected using a plastic syringe. Cores were frozen for 2 wk at 240uC. Upon defrosting, samples were homogenized and washed through a $4 \mathrm{w}(63 \mathrm{~mm})$ sieve. The fine fraction, which washed through the sieve, was diluted to $1,000 \mathrm{ml}$ in a graduated cylinder. It was carefully mixed by moving a plastic rod up and down, from bottom to top, for exactly $1 \mathrm{~min}$. The sample was left to settle for $1 \mathrm{~min}$ and $56 \mathrm{~s}$, at which time a $20 \mathrm{ml}$ sample was taken from a depth of $10 \mathrm{~cm}$ (see Folk 1974 for a full description of pipette analysis). All water was removed from the sample by drying it to constant weight at $85 \mathrm{uC}$. The dry weight of this subsample was used to calculate the total amount of sediment less than $63 \mathrm{~mm}$ in diameter present in the core. Sediment retained on the $4 \mathrm{~W}$ sieve was dried to constant weight at 85uC. This sediment was sorted into fractions by mechanically shaking a column of sieves of mesh sizes $0 \mathrm{w}(1 \mathrm{~mm}), 1 \mathrm{w}(500 \mathrm{~mm}), 2 \mathrm{w}$ $(250 \mathrm{~mm}), 2.5 \mathrm{w}(177 \mathrm{~mm}), 3 \mathrm{w}(125 \mathrm{~mm}), 3.5 \mathrm{w}$ $(88 \mathrm{~mm})$, and $4 \mathrm{w}(63 \mathrm{~mm})$ for $10 \mathrm{~min}$ using a RoTap (Tyler) shaker. The dry weight of each fraction was determined and the proportion each contributed to total mass was calculated.
To test whether macroinvertebrate assemblages vary spatially according to sedimentology or exposure to boat wake, 5 samples of infauna and five samples of epifauna were collected from each site. Infauna were sampled by collecting cylindrical cores of sediment, $10 \mathrm{~cm}$ in diameter and $10 \mathrm{~cm}$ deep, from unvegetated sediment adjacent to seagrass patches. Epifauna were sampled by placing circular quadrats, $10 \mathrm{~cm}$ in diameter, over seagrass blades on the edges of patches and collecting all material within each quadrat by carefully cutting the seagrass just above the substratum and placing the seagrass and attached epiphytes slowly and carefully into plastic bags so that mobile epifauna stayed within the cut clumps. Samples were placed on ice and transported to the laboratory, where they were washed over a $500 \mathrm{~mm}$ mesh. The portion of the sample retained by the sieve was preserved in $7 \%$ formalin and stained with Rose Bengal.

A pair of forceps was run along the length of each blade of seagrass to remove all epifauna. Infaunal invertebrates were separated from the sediment. Polychaetes were sorted to family, crustaceans to order, and bivalves and gastropods to species. This approach shortened the time needed to process samples and is unlikely to have compromised the usefulness of the data in demonstrating spatial differences. Chapman (1998) showed that similar patterns of benthic assemblages are often found when either mixed or finer levels of taxonomic resolution are used.

Although I determined the dry weight of seagrass blades within each core by drying aboveground plant material to constant weight at $80 \mathrm{uC}$, analyses indicated abundances of macroinvertebrates did not need to be standardized according to biomass of seagrass blades before testing for differences in epifaunal assemblages among treatments. The dry weight of seagrass blades in samples did not differ among treatments (analysis of variance [ANOVA]: $\mathrm{p}$ 5 0.80). A Spearman's rank correlation between normalized Euclidean distances for pairwise comparisons of dry weights of seagrass blades and BrayCurtis dissimilarities for comparisons of invertebrate assemblages was nonsignificant ( $\mathrm{r} 5$ 0.096, p 5 0.12 , df 5 28).

Hypothesized differences in sedimentology and assemblages of invertebrates between sites were examined using nonmetric multidimensional scaling (nMDS: Shephard 1962; Kruskal 1964) of raw data. Euclidean distances were used for ordination of sedimentological data. Separate ordinations of infaunal and epifaunal macroinvertebrates were based on matrices of Bray-Curtis dissimilarities between samples (Bray and Curtis 1957), calculated from untransformed counts. 
To test whether the granulometry of sites was related to their situation on natural banks of the sound or dredge spoil islands a two-way nested Permutational Multivariate Analysis of Variance (PERMANOVA) (Anderson 2001) with the factors treatment $(+\mathrm{W}+\mathrm{S}, 2 \mathrm{~W}+\mathrm{S}, 2 \mathrm{~W} 2 \mathrm{~S})$ and site within treatment were performed on Euclidean distances between sediment samples. Similarity percentages (SIMPER) analysis (Clarke 1993) identified sediment fractions most important in contributing to any multivariate differences among treatments. Nested ANOVA with two factors, treatment and site, were performed on these fractions to test for effects of treatment.

If the previous deposition of fine materials is more important than wake in determining the structure of invertebrate assemblages, the assemblages of spoil affected sites should be more similar to one another than to those without spoil, irrespective of wake exposure. If wake exposure is the more important factor, dissimilarity between sites with or without wake will exceed dissimilarity between sheltered (2W) sites with or without spoil. This was tested using one-way ANOVA on BrayCurtis measures of dissimilarity between faunal samples. To provide independent measures for analysis (Underwood and Chapman 1998), each site was paired only once, as were replicates within pairings of sites.

Where a significant effect of either treatment on assemblages of macroinvertebrates was found, SIMPER (Clarke 1993) analyses were performed to identify taxa contributing most to this pattern. ANOVA were performed on these taxa to test for differences among treatments. Data were transformed using $\ln (\mathrm{x}+1)$ to reduce heterogeneity in variances and ensure that Cochran's C-test (1951) would not be significant at a 50.05 .

\section{Results}

Ordination and PERMANOVA analysis of grain size distributions separated sites into two groups according to their situation along the natural banks of the sound or adjacent to dredge spoil islands (PERMANOVA: $F_{2,3} 5$ 0.192, p 5 0.035; Fig. 2). Among spoil affected sites granulometry was similar between places with and without wake (a posteriori tests, PERMANOVA: +W+S 5 2W+S ? 2W2S). SIMPER analysis indicated that differences in granulometry among sites were primarily due to differences in the proportion of very fine sand (3.5 - w - 3) and medium sand (2.5 - w - 2) they contained. Very fine sand contributed $30-40 \%$ of variability between pairs of treatments and medium sands contributed 19-32\%. Sites without dredge spoil contained greater proportions by weight of medium sands and smaller proportions of very fine

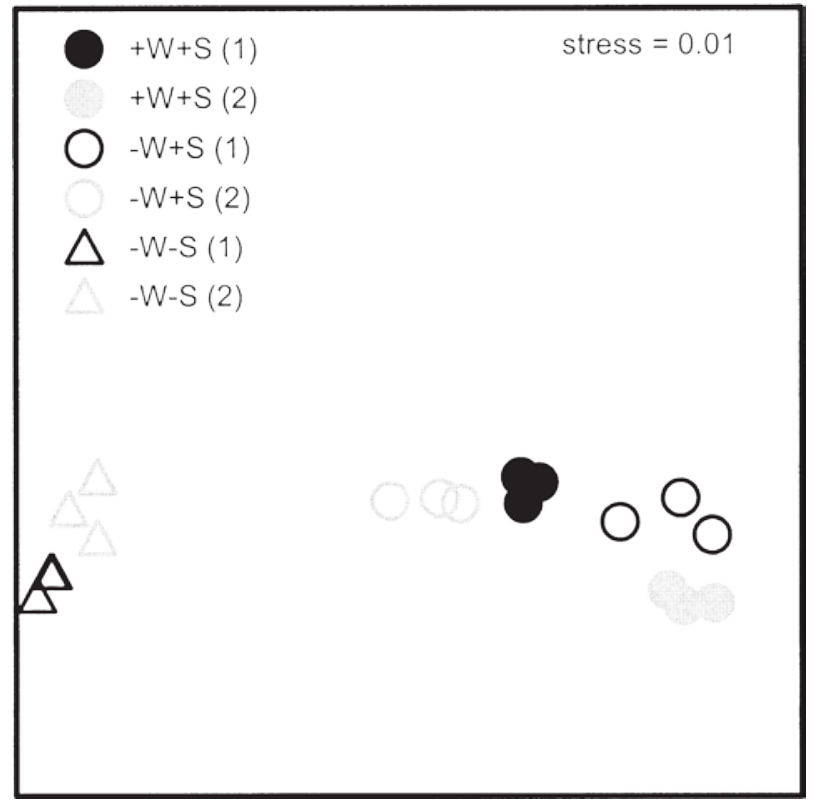

Fig. 2. nMDS ordination of grain size distributions of sediments collected just outside patches of seagrass at each of the sites. Points represent individual samples. +W $\mathbf{5}$ with wake, 2W 5 without wake, +S 5 with spoil, and 2S 5 without spoil.

sands than sites with dredged materials (Table 1 and Fig. 3), so sediments along the natural banks were coarser than those adjacent to spoil islands.

In contrast to the sediments, invertebrate fauna did not form distinct groupings on nMDS plots (Fig. 4). Infaunal assemblages at spoil affected sites, with or without wake, were more similar to one another than they were to assemblages at sites without spoil or wake (Table 2 and Fig. 5). Sites without wake had more similar epifaunal assemblages to one another than to sites with wake, irrespective of whether they were affected by spoil.

Of the 63 infaunal taxa identified in cores of sediment, SIMPER identified Amphipoda as the most important in contributing to the difference in assemblages between spoil affected and sedimentologically natural sites, accounting for $21 \%$ of dissimilarity between these groups. Nereididae (10\%), Paraonidae (8\%), Lumbrineridae (6\%), Nematoda (5\%), and Syllidae (3\%) were the next most important contributors. Of these, only Paraonidae and Syllidae displayed patterns consistent with granulometry, having greater abundances on the natural bank than on the dredge spoil islands (Table 3 and Fig. 6).

SIMPER indicated that dissimilarity in the assemblages of seagrass blades between wake exposed and sheltered treatments was largely due to differing abundances of the epifaunal gastropod Bittiolum varium. This taxon, which explained $47 \%$ of the 
TABLE 1. ANOVA comparing the percent contribution of sediment fractions identified as principle contributors to multivariate patterns and total weight at sites at Bogue Sound, North Carolina. There were 3 levels of treatment (with wake and spoil [+W+S], without wake but with spoil $[2 \mathrm{~W}+\mathrm{S}]$, without wake or spoil [2W2S]), and 2 levels of Site (treatment) (random). * p - 0.05. n 53.

\begin{tabular}{|c|c|c|c|c|c|c|c|}
\hline & \multirow[b]{3}{*}{ df } & \multicolumn{3}{|c|}{ Very Fine Sand } & \multicolumn{3}{|c|}{ Medium Sand } \\
\hline & & \multicolumn{3}{|c|}{$(3.5-W-3)$} & \multicolumn{3}{|c|}{$(2.5-W-2)$} \\
\hline & & MS & $\bar{F}$ & $\mathrm{p}$ & MS & $\bar{F}$ & $\mathrm{p}$ \\
\hline Treatment & 2 & 1142 & 14.4 & 0.03 & 672 & 23.5 & 0.01 \\
\hline Site (treatment) & 3 & 78 & 41.3 & 0.00 & 29 & 27.6 & 0.00 \\
\hline Residual & 12 & 2 & & & 1 & & \\
\hline Cochran's test & & & 50.5 & & & 50.4 & \\
\hline SNK & & & $2 \mathrm{~W}+\mathrm{S}$ & & & $\mathrm{W}+\mathrm{S}$ & \\
\hline
\end{tabular}

variation between treatments, was more abundant (although not significantly so; Table 3) at sites with wake than sites without wake (Fig. 7). The slipper limpet, Crepidula fornicata, also displayed this pattern.

\section{Discussion}

Among the effects of boat generated waves on sedimentary habitats is the resuspension and erosion of fine sediments to leave only coarser grained materials (Garrad and Hey 1987; Nanson et al. 1994; Osborne and Boak 1999; Bauer et al. 2002). Coarsening of sediments may substantially alter

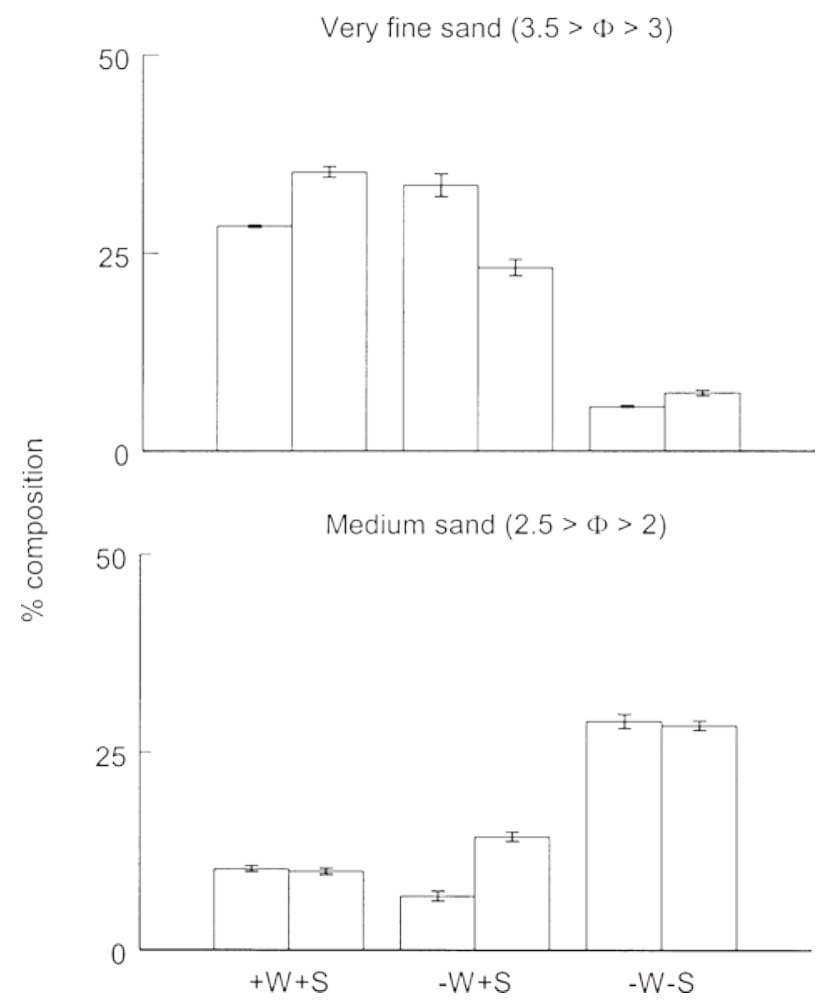

Fig. 3. Mean (+ 1 SE) percent contribution of dominant sediment fractions to total weight at each of the sites sampled along Bogue Sound. +W 5 with wake, 2W 5 without wake, +S 5 with spoil, and 2S 5 without spoil. n 53 . spatial patterns of infaunal species of macroinvertebrate that have distributions closely correlated to certain types of sediment (Rhoads 1974; Snelgrove and Butman 1994). In many places where boating occurs, sediments are also affected by the routine disposal of dredge spoil from boat channels as well as boat wake. Because dredge spoil is generally fine

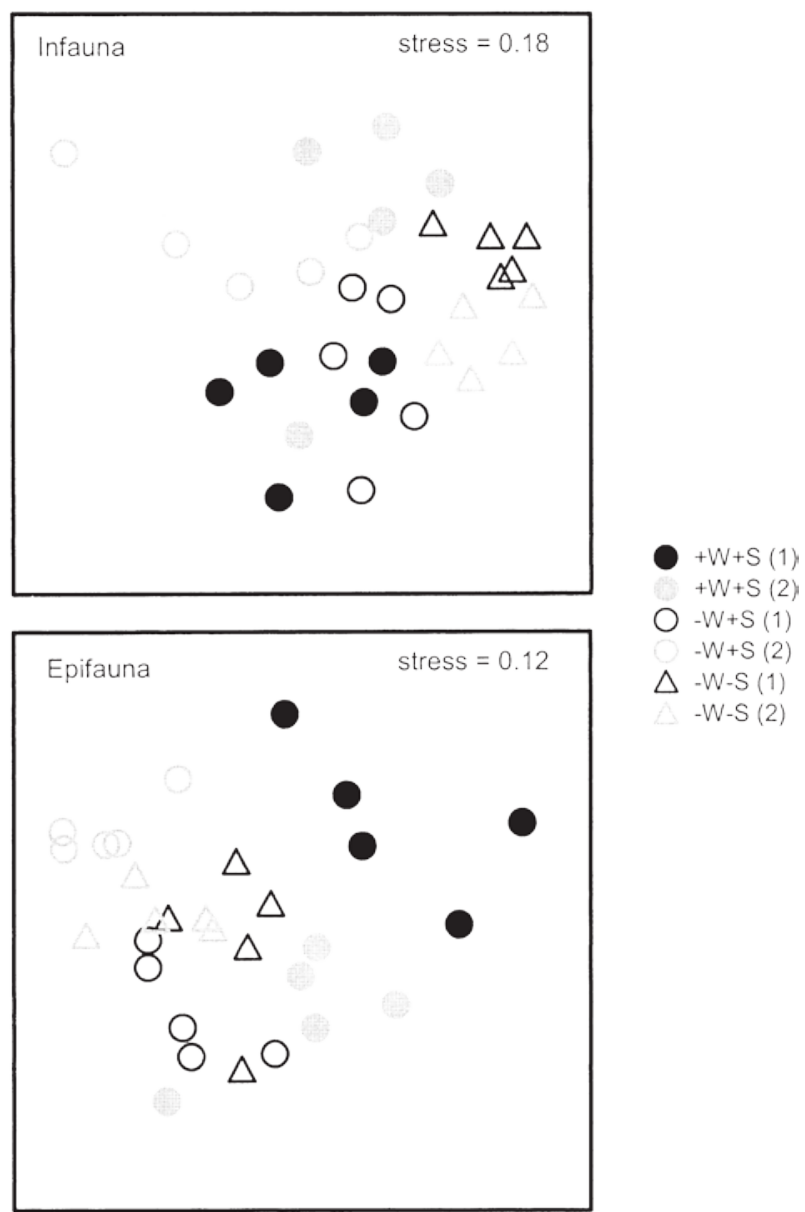

Fig. 4. nMDS ordinations of assemblages of macroinvertebrates collected from sites within Bogue Sound. Points represent individual samples. +W 5 with wake, $2 \mathrm{~W} 5$ without wake, +S 5 with spoil, and 2S 5 without spoil. 
TABLE 2. ANOVA testing for differences in the magnitude of Bray Curtis measures of dissimilarity in composition of macroinvertebrates between pairs of treatments. 15 with wake and spoil versus without wake but with spoil, 25 with wake and spoil versus without wake or spoil, and 35 without wake but with spoil versus without wake or spoil. n 5 5. * 5 p - 0.05 .

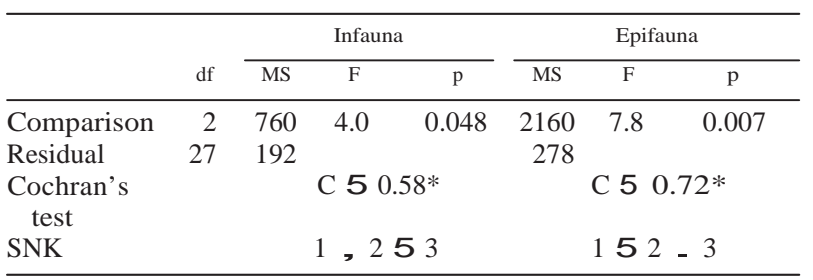

grained, this disturbance may have an effect on sediments that is compensatory to that of boat wake. In this case, an effect of boat wake on infaunal assemblages of unvegetated sediments may not be seen even though hydrodynamic forces are large enough to affect distributions of epifaunal macroinvertebrates associated with adjacent patches of seagrass.

In Bogue Sound, North Carolina, exposure to boat wake did not influence infaunal assemblages in spoil-affected sediments despite strong effects of boat wake on epifauna. The structure of infaunal assemblages was similar between sheltered and exposed sides of dredge spoil islands and instead differed between dredge spoil islands and sites lacking spoil. Paranoids and syllids were more abundant at sites without spoil than on dredge spoil islands, but did not differ between sites with and sites without wake. The lack of an effect of wake on infauna, despite the detection of strong effects of similarly sized waves by other studies (Bishop and Chapman 2004), may be because any effect of wake on grain size was masked by dredge disposal, which decreased grain size. Epifaunal assemblages, presumably less influenced by sediment granulometry, differed between sites without wake and with wake irrespective of previous spoil disposal.

Although this study did not directly manipulate boat wake to demonstrate its role in structuring assemblages, wake appears the most likely candidate in producing the epifaunal distributions observed here. Although exposure to wind-driven waves may have differed between sites on the north-facing $(+W)$ and south-facing (2W) sides of the spoil islands, differences in epifaunal assemblages between north-facing sites with and without wake were detected despite similar exposure to wind generated waves, so wind generated waves alone cannot explain differences in epifauna among sites. Among site differences in epifaunal distributions do not appear to be due to contaminants emitted by boats, because hydrodynamic mixing occurs between the

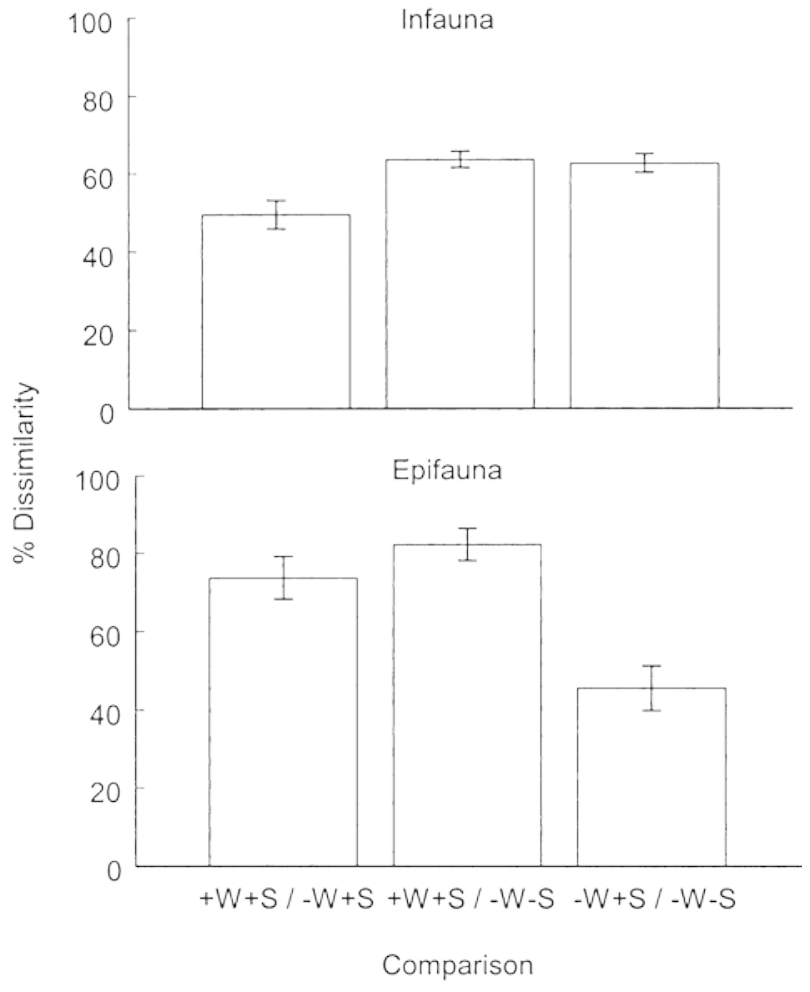

Fig. 5. Mean (+ 1 SE) Bray-Curtis dissimilarity in assemblages of macroinvertebrates between treatments. $+\mathrm{W} 5$ with wake, $2 \mathrm{~W}$ 5 without wake, +S 5 with spoil, and 2S 5 without spoil. n 55 .

two halves of the sound, exposing all sites to contaminants.

The molluscs, B. varium and C. fornicata, contributed most to epifaunal differences between sheltered and exposed sites. Each was less abundant at sites with wake than at sites without wake, irrespective of sediment granulometry. Decreased abundances of these taxa at exposed sites may have been due to inhibition of feeding by the resuspension of fine dredge materials. As a suspension feeder, C. fornicata is known to be particularly sensitive to resuspended sediments (Newell and Kofoed 1977). The effect may have been a direct result of increased hydrodynamic forces. B. varium and C. fornicata, as mobile epifuanal taxa, only loosely attach to seagrass blades so may easily be displaced during flapping of seagrass blades, induced by the orbital motion of waves (Grizzle et al. 1996; Koch and Gust 1999). Their abundances will be permanently depressed following displacement if they are incapable of recolonizing blades (e.g., adult C. fornicata, Hoagland 1978), they are more susceptible to predation during the period of displacement (see Warren 1985), or the time required for recolonization of blades is greater than the frequency of the disturbance. Wave-induced flapping of blades could 
TABLE 3. ANOVA comparing abundances of macroinvertebrates among the 3 treatments (with wake and spoil [+W+S], without wake but with spoil $[2 \mathrm{~W}+\mathrm{S}]$, and without wake or spoil [2W2S]). All data were $\ln (\mathrm{x}+1)$ transformed prior to analysis. n $55 . * 5 \mathrm{p}-0.05$.

\begin{tabular}{|c|c|c|c|c|c|c|c|}
\hline & df & MS & F & $\mathrm{p}$ & MS & F & $\mathrm{p}$ \\
\hline Infauna & & \multicolumn{3}{|c|}{ Paraonidae } & \multicolumn{3}{|c|}{ Syllidae } \\
\hline Treatment & 2 & 3.40 & 9.08 & 0.05 & 7.19 & 28.69 & 0.01 \\
\hline Sites (treatment) & 3 & 0.37 & 0.99 & 0.42 & 0.25 & 0.95 & 0.43 \\
\hline Residual & 24 & 0.38 & & 0.26 & & & \\
\hline Cochran's test & & \multirow{2}{*}{\multicolumn{3}{|c|}{$\begin{array}{c}\text { C } 50.27 * \\
+W+S 52 W+S, 2 W 2 S\end{array}$}} & \multirow{2}{*}{\multicolumn{3}{|c|}{$\begin{array}{c}\text { C } 50.47^{*} \\
+\mathrm{W}+\mathrm{S} 52 \mathrm{~W}+\mathrm{S}, 2 \mathrm{~W} 2 \mathrm{~S}\end{array}$}} \\
\hline SNK & & & & & & & \\
\hline Epifauna & & \multicolumn{3}{|c|}{ Bittiolum varium } & \multicolumn{3}{|c|}{ Crepidula fornicata } \\
\hline Treatment & 2 & 15.07 & 2.62 & 0.22 & 6.58 & 39.91 & 0.01 \\
\hline Sites (treatment) & 3 & 5.76 & 5.46 & 0.00 & 0.16 & 0.47 & 0.70 \\
\hline Residual & 24 & 1.05 & & & 0.35 & & \\
\hline Cochran's test & & \multirow{2}{*}{\multicolumn{3}{|c|}{ C 5 0.22* }} & \multirow{2}{*}{\multicolumn{3}{|c|}{$\begin{array}{c}\text { C } 50.37 * \\
+W+S, 2 W+S 52 W 2 S\end{array}$}} \\
\hline SNK & & & & & & & \\
\hline
\end{tabular}

also influence faunal assemblages by improving accessibility of epifaunal assemblages to predatory fish.

Boat wake may also have indirectly affected the faunal assemblages of seagrass via changes in the morphology of the seagrass beds themselves. The perimeter to area ratio of seagrass patches, an important determinant of the susceptibility of prey residing in patches to predators that forage from

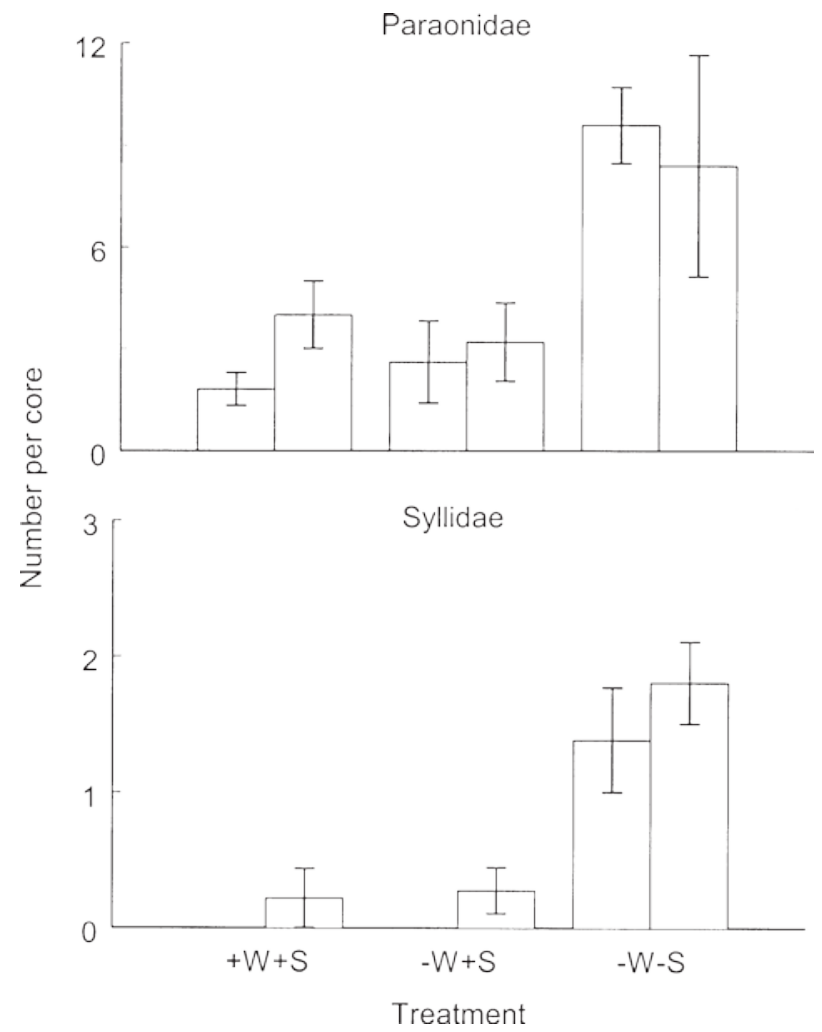

Fig. 6. Mean (+ 1 SE) abundance of infaunal taxa in cores of sediment collected from sites at Bogue Sound. +W 5 with wake, 2W 5 without wake, +S 5 with spoil, and 2S 5 without spoil. n 55 . patch to patch, generally increases with wave exposure (Fonseca and Bell 1998). Exposure can also decrease shoot densities and as a result, the foraging efficiency of predators resident within patch (see Heck and Thoman 1981). Although the landscape-scale morphology of seagrass beds was not quantified here, biomass did not differ between seagrass patches in exposed and sheltered areas.

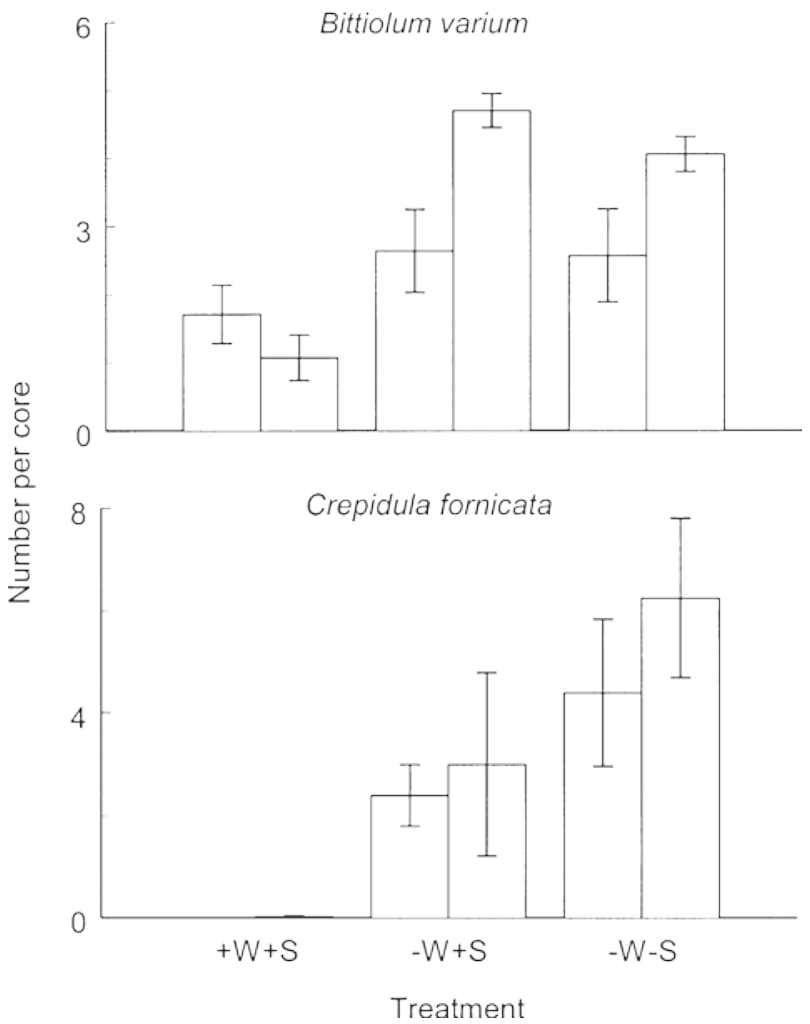

Fig. 7. Mean (+1 SE) abundance of epifaunal taxa in cores of seagrass collected from sites at Bogue Sound. +W 5 with wake, 2W 5 without wake, +S 5 with spoil, and 2S 5 without spoil. n 55 . 
The results of this study have important implications for the management of coastal systems. Boating activity is commonly managed to minimize physical damage to structures. For example, nowake zones, where vessels must slow to minimize the production of wake, may be implemented in unvegetated areas to reduce erosion of fine sediments. Sampling of sediments and fauna suggests that despite the absence of a sedimentological signal associated with wake, a significant effect of this disturbance on assemblages of seagrass occurred. Ecological impacts do not necessarily mirror physical effects and should be considered separately from physical effects when adopting strategies of management. This study also demonstrates that in environments where multiple disturbances co-occur, compensatory effects of multiple disturbances can occur on some but not all components of the environment. A holistic approach to ecological impact assessment, in which effects of co-occurring disturbances are considered together, not separately, is required.

\section{ACKNOWLEDGMENTS}

This work was funded by an Australian Postgraduate Award, the James King of Irrawang Scholarship, and the R. and $\mathrm{M}$. Bentwich Scholarship for overseas travel (University of Sydney) and funds from the Australian Research Council through the Special Centre for Research on Ecological Impacts of Coastal Cities. C. H. Peterson at the University of North Carolina at Chapel Hill Institute of Marine Sciences allowed use of the facilities of his lab for the collection and processing of samples and provided useful feedback on this manuscript. H. Summerson and D. Gaskill helped with fieldwork. This manuscript benefited greatly from the constructive comments of three anonymous reviewers.

\section{Literature Cited}

Anderson, M. J. 2001. A new method for non-parametric multivariate analysis of variance. Austral Ecology 26:32-46.

Bauer, B. O., M. S. Lorang, and D. J. Sherman. 2002. Estimating boat-wake-induced levee erosion using sediment suspension measures. Journal of Waterway, Port and Coastal Oceanography and Engineering 128:152-162.

Bayne, B. L., A. J. S. Hawkins, E. Navarro, and J. I. P. Iglesias. 1989. Effects of seston concentration on feeding, digestion and growth in the mussel Mytilus edulis. Marine Ecology Progress Series 55:47-54.

Bell, S. S., M. O. Hall, S. Soffian, and K. Madley. 2002. Assessing the impact of boat propeller scars on shrimp and fish utilizing seagrass beds. Ecological Applications 12:206-217.

Bishop, M. J. 2004. A posteriori evaluation of strategies of management: The effectiveness of no-wash zones in minimizing the impacts of boat-wash on macrobenthic infauna. Environmental Management 34:140-149.

Bishop, M. J. AND M. G. ChApMAn. 2004. Managerial decisions as experiments: An opportunity to determine the ecological impact of boat-generated waves on macrobenthic infauna. Estuarine Coastal and Shelf Science 61:613-622.

Bock, M. J. AND D. C. Miller. 1994. Seston variability and daily growth in Mercenaria mercenaria on an intertidal sandflat. Marine Ecology Progress Series 114:117-127.
BRAY, J. R. AND J. T. CURTIS. 1957. An ordination of the upland forest communities of southern Wisconsin. Ecological Monographs 27:325-349.

Bricelu, V. M., R. E. Malouf, and C. Dequillfeldt. 1984. Growth of juvenile Mercenaria mercenaria and the effect of resuspended bottom sediments. Marine Biology 84:167-173.

Bryan, G. W., P. E. Gibbs, L. G. Hummerstone, and G. R. Burt. 1986. The decline of the gastropod Nucella lapillus around south-west England: Evidence for the effect of tributyltin from antifouling paints. Journal of the Marine Biological Association of the U.K. 66:611-40.

Chapman, M. G. 1998. Relationships between spatial patterns of benthic assemblages in a mangrove forest using different levels of taxonomic resolution. Marine Ecology Progress Series 162:71-78.

Clarke, K. R. 1993. Non-metric multivariate analyses of changes in community structure. Australian Journal of Ecology 18:117-143.

Cochran, W. G. 1951. Testing a linear relation among variances. Biometrics 7:17-32.

DAVIS, G. E. 1977. Anchor damage to a coral reef on the coast of Florida. Biological Conservation 11:29-34.

Denny, M. W. 1987. Life in the maelstrom: The biomechanics of wave-swept rocky shores. Trends in Ecology and Evolution 2:61-66.

DenNy, M. W. 1995. Predicting physical disturbance: Mechanistic approaches to the study of survivorship on wave-swept shores. Ecological Monographs 65:371-418.

Denny, M. W., T. L. Daniel, And M. A. R. Koehl. 1985. Mechanical limits to size in wave-swept organisms. Ecological Monographs 55:69-102.

DobBs, F. C. AND J. M. Vozarik. 1983. Immediate effects of a storm on coastal infauna. Marine Ecology Progress Series 11:273-279.

Emerson, C. W. AND J. Grant. 1991. The control of the soft-shell clam (Mya arenaria) recruitment on intertidal sandflats by bedload sediment transport. Limnology and Oceanography 36:1288-1300.

FolK, R. L. 1974. Petrology of Sedimentary Rocks. Hemphill Publishing Company, Austin, Texas.

FonSECA, M. S. AND S. S. BELL. 1998. Influence of physical setting on seagrass landscapes near Beaufort, North Carolina USA. Marine Ecology Progress Series 171:109-121.

Garrad, P. N. AND R. D. Hey. 1987. Boat traffic, sediment resuspension and turbidity in a broadland river. Journal of Hydrology 95:289-297.

Glasby, T. M. AND S. D. Connell. 2001. Orientation and position of substrata have large effects on epibiotic assemblages. Marine Ecology Progress Series 214:127-135.

Gosselink, J. G., G. P. Shaffer, L. C. Lee, D. M. Burdick, D. L. Childers, N. C. Leibowitz, S. C. Hamilton, R. Boumans, D. Cushman, S. Fields, M. Koch, and J. M. Visser. 1990. Landscape conservation in a forested wetland watershed: Can we manage cumulative impacts? BioScience 40:588-600.

Grant, J. AND B. THORPE. 1991. Effects of suspended sediment on growth, respiration, and excretion of the soft shell clam (Mya arenaria). Canadian Journal of Fisheries and Aquatic Sciences 48:1285-1292.

Grizzle, R. E., F. T. Short, C. R. Newell, H. Hoven, AND L. KINDBLOM. 1996. Hydrodynamically induced synchronous waving of seagrasses: 'Monami' and its possible effects on larval mussel settlement. Journal of Experimental Marine Biology and Ecology 206:165-177.

Heck, K. L. And T. A. Thoman. 1981. Experiments on predatorprey interactions in vegetated aquatic habitats. Journal of Experimental Marine Biology and Ecology 53:125-134.

HoAgland, K. E. 1978. Protandry and the evolution of environmentally mediated sex exchange: A study of the Mollusca. Malacologia 17:365-391.

Koch, E. W. AND G. Gust. 1999. Water flow in tide- and wavedominated beds of the seagrass Thalassia testudinum. Marine Ecology Progress Series 184:63-72.

KRUSKAL, J. B. 1964. Multidimensional scaling by optimizing goodness of fit to a nonmetric hypothesis. Psychometrika 29:1-27. 
MacIntyre, H. L. AND J. J. Cullen. 1996. Primary production by suspended and benthic microalgae in a turbid estuary: Timescales of variability in San Antonio Bay, Texas. Marine Ecology Progress Series 145:245-268.

Nanson, G. C., A. Vonkrusnstierna, E. A. Bryant, And M. R. RENILSON. 1994. Experimental measures of river-bank erosion caused by boat-generated waves on the Gordon River, Tasmania. Regulated Rivers Research and Management 9:1-14.

Newell, R. C. AND L. H. Kofoed. 1977. The energetics of suspension-feeding in the gastropod Crepidula fornicata L. Journal of the Marine Biological Association of the United Kingdom 57:161-180.

Osborne, P. D. And E. H. BoAK. 1999. Sediment suspension and morphological response under vessel-generated wave groups: Torpedo Bay, Auckland, New Zealand. Journal of Coastal Research 15:388-398.

RHOADS, D. C. 1974. Organism-sediment relations on the muddy sea floor. Oceanography and Marine Biology: An Annual Review 12:263-300.

SHEPHARD, R. N. 1962. The analysis of proximities: Multidimensional scaling with an unknown distance function. Psychometrika 27:125-140.

Snelgrove, P. V. R. And C. A. Butman. 1994. Animal-sediment relationships revisited: Cause versus effect. Oceanography and Marine Biology: An Annual Review 32:111-177.

Spaling, H. AND B. Smit. 1993. Cumulative environmental change: Conceptual frameworks, evaluation approaches, and institutional perspectives. Environmental Management 17:587-600.
TAMAKI, A. 1987. Comparison of resistivity to transport by wave action in several polychaete species on an intertidal sand flat. Marine Ecology Progress Series 37:181-189.

Turner, S. J., J. E. Hewitt, M. R. Wilkinson, D. J. Morrisey, S. F. Thrush, V. J. Cummings, And G. Funnell. 1999. Seagrass patches and landscapes: The influence of wind-wave dynamics and hierarchical arrangements of spatial structure on macrofaunal seagrass communities. Estuaries 22:1016-1032.

Underwood, A. J. AND M. G. CHAPMAN. 1998. A method for analysing spatial scales of variation in composition of assemblages. Oecologia 117:570-578.

Vouk, V. B., G. C. Butler, A. C. Upton, D. V. Parke, and S. C. Asher (eds.). 1987, Methods for Assessing the Effects of Mixtures of Chemicals, Scientific Group on Methodologies for the Safety Evaluation of Chemicals (SGOMSEC) 3, Scientific Committee on Problems of the Environment (SCOPE) 30. John Wiley and Sons, Chichester, U.K.

Walker, D. I., R. J. Lukatelich, G. Bastyan, and A. J. McComb. 1989. Effect of moorings on seagrass beds near Perth, Western Australia. Aquatic Botany 36:69-77.

WARren, J. H. 1985. Climbing as an avoidance behaviour in the salt marsh periwinkle, Littorina irrorata. Journal of Experimental Marine Biology and Ecology 89:11-28.

Received, June 11, 2004

Revised, February 28, 2005

Accepted, March 28, 2005 